\title{
Rate of Carotenoid Degradation in Dehydrated Carrots
}

Lavelli, V. ${ }^{\text {a.; Zanoni, B. }}{ }^{\text {b. Zaniboni, A. }}{ }^{\text {a }}$

a DISTAM, Dipartimento di Scienze e Tecnologie Alimentari e Microbiologiche, Università degli Studi di Milano, via Celoria 2, 20133 Milano, Italy

${ }^{b}$ DiBA, Sezione Tecnologie Alimentari, Università degli Studi di Firenze, via Donizetti 6, 50144 Firenze, Italy

\section{Abstract}

This work was focused on dehydrated carrots with the aim to study: a) the water sorption properties, and b) the rate of carotenoid degradation as a function of water activity.

Freeze-dried carrots from blanched and not blanched batches were placed in air-tight glass jars containing saturated salt solutions with water activity ranging from 0.052 to 0.75 , at $40^{\circ} \mathrm{C}$. The equilibrium moisture, water activity, and carotenoid content were analysed at different storage times.

Results showed that the adsorption isotherm fitted the Guggenheim-Andersonde-Boer $(G A B)$ equation $\left(R^{2}=99.65 \%\right)$. Estimated monolayer water activity was 0.33 (confidential limits at 95\%: 0.26 and 0.38 ).

$\alpha$ - and $\beta$-Carotene contents decreased in all dehydrated carrots following pseudo-first-order kinetics, with rate constants ranging from 0.031 to 0.374 days ${ }^{-1}$. Similar rate constants were found between $\alpha$ - and $\beta$-carotene.

In all carrot batches the rate of carotenoid degradation was at a minimum within the water activity range $0.31-0.54$. Below and above this range the rate of carotenoid degradation increased significantly.

Blanching resulted in a higher initial carotenoid content, but it accelerated carotenoid decrease during storage of dehydrated carrots.

Based on these results we concluded that two strategies could be useful to increase carotenoid stability during storage:

a) the development of intermediate moisture carrots (water activity in the range $0.31-0.54$ );

b) the identification of protective factors that can increase carotenoid stability at water activity above 0.54 .

Both criteria should be combined with optimised packaging conditions, which reduce exposure of product to air and light during storage.

Keywords: carrot, water activity, GAB model, carotenoid

\section{Introduction}

Vitamin A deficiency is the leading cause of blindness in children in developing countries. Dietary intervention with foods rich in pro-vitamin A, such as carrots, has been suggested as one solution to this problem (El-Arab et al., 2002). In addition, due to their antioxidant activity, carotenoids may also be beneficial in preventing major health problems such as cancer, cardiovascular/coronary heart diseases, and other diseases (Yeum and Russell, 2002). 
Previous studies in our laboratory demonstrated that the carotenoid content of minimally-processed carrots did not decrease during storage, however, these products are degraded by microbial spoilage and accelerated metabolic activity (Lavelli et al., 2006; Zanoni et al., 2006).

Reducing the water activity $\left(a_{w}\right)$ results in a longer shelf-life of carrots, though carotenoids degrade faster in dehydrated systems, through autocatalytic oxidation (Goldman et al., 1983). The influence of $a_{w}$ on oxidation is complex. Increasing the water content in dry matrices may increase the rate of oxidation by enhancing the mobility of reactants and bringing catalysts into solution. As the solid matrix swells, new surfaces for catalysts are exposed. However, water may also slow up oxidation by hydrating or diluting heavy metal catalysts or precipitating them as hydroxides. Water may also counteract peroxide decomposition by hydrogen bonding with hydroperoxides, and encourage radical recombination which could interrupt the oxidation reaction chain. The net result of all these actions is that, in many foods, the rate of oxidation reaches a minimum in the $a_{w}$ corresponding to the monomolecular moisture content (Brennan, 1994). Therefore, it is suggested that dehydrated foods should be stored at a monolayer $a_{w}$ to decrease oxidative degradations and thus extend their shelf-life.

Knowledge on the water sorption properties of different food matrices would be helpful in order to predict the relative rate of oxidative degradations. Literature data on the sorption properties of carrots are incomplete and contradictory results have been reported on the monolayer $\mathrm{a}_{\mathrm{w}}$ (Kiranoudis et al., 1993; Iglesias and Chirife, 1982). While studies on carotenoid stability have been mainly carried out on model systems simulating dehydrated foods, little information is available on carotenoid stability in carrots at intermediate $a_{w}$ values.

This work was focused on dehydrated carrots with the aim to study: a) the water sorption properties, and b) the rate of carotenoid degradation as a function of $a_{w}$.

\section{Materials and Methods}

Carrots. Two batches of carrots were obtained from the wholesale fruit and vegetable distribution center of Milan (Italy). Manually, they were sorted, peeled, washed with cold water, dripped, discarded of upper and lower ends and half-sliced. Half-carrots were cut in sticks "Julienne type" by a vegetable cutter (Mouli Julienne mod. A44506, Moulinex, Milan, Italy). The first batch (sample 1 NB) and a part of the second batch (sample $2 \mathrm{NB}$ ) of sticked carrots were not blanched whereas the other part of the second batch was blanched in boiling water for $1 \mathrm{~min}$ (sample $2 \mathrm{~B}$ ). Blanched and not-blanched carrots were dehydrated by freeze drying in a Lyoflex Edwards (Crawley, UK) apparatus.

Storage study. About $0.5 \mathrm{~g}$ of freeze-dried samples were placed into Petri dishes (4 cm diameter) to allow for a high surface area between air and powder during storage, and then into thermostated air-tight glass jars containing saturated salt solutions (Table 1 ), at $40^{\circ} \mathrm{C}$. The equilibrium moisture content was reached within 2 days.

It may be hypothesized that prior to the equilibrium the water content was not homogeneous in the carrots, in spite of a large surface area between the carrots and the air. Water gradients within the samples result in different carotenoid degradation rates, therefore, the non-equilibrium period was not studied. Samples were analyzed 
after two days of incubation, for zero time, and periodically for 30 days. Duplicate Petri dishes were removed from the jars for each measurement.

Table 1. Water Activity Values for Saturated Salt Solutions at $40^{\circ} \mathrm{C}$

\begin{tabular}{lc}
\hline Saturated salt solution & $\mathrm{a}_{\mathrm{w}}{ }^{\mathrm{a}}$ \\
\hline $\mathrm{LiBr}$ & $0.0580 \pm 0.0039$ \\
$\mathrm{ZnBr} 2$ & $0.0754 \pm 0.0020$ \\
$\mathrm{LiCl}$ & $0.1121 \pm 0.0021$ \\
$\mathrm{KF}$ & $0.2268 \pm 0.0081$ \\
$\mathrm{MgCl}$ & 2 \\
$\mathrm{NaBr}$ & $0.3160 \pm 0.0013$ \\
$\mathrm{KI}$ & $0.5317 \pm 0.0041$ \\
$\mathrm{NaCl}$ & $0.6609 \pm 0.0023$ \\
\hline
\end{tabular}

${ }^{\mathrm{a}}$ As reported by Greenspan (1977)

Moisture content and $a_{w}$. Moisture contents of carrots were determined using a vacuum oven at $70^{\circ} \mathrm{C}$ and 50 torr for $6 \mathrm{~h}$ (AOAC, 1980). $A_{w}$ of carrots and of saturated salt solutions was measured by a dew point hygrometer (Aqualab, Decagon Devices, WA, USA). Triplicate determinations were made for each sample.

Modelling of sorption isotherm. The Guggenheim-Anderson-de Boer (GAB) equation was applied to model experimental data for $n_{s}$ as a function of $a_{w}$, as recommended by Spiess and Wolf (1987). The GAB model is expressed as follows:

$\mathrm{n}_{\mathrm{s}}=\mathrm{n}_{\mathrm{sm}} \mathrm{Cka} \mathrm{w}_{\mathrm{w}} /\left[\left(1-k \mathrm{a}_{\mathrm{w}}\right)\left(1-\mathrm{ka} \mathrm{a}_{\mathrm{w}}+\mathrm{Cka} \mathrm{w}_{\mathrm{w}}\right)\right]$

where $\mathrm{n}_{\mathrm{s}}$ is the equilibrium moisture content on dry basis; $\mathrm{n}_{\mathrm{sm}}$ is the monolayer moisture content on dry basis; $\mathrm{C}$ and $\mathrm{k}$ are related to the temperature effect through the equations:

$\mathrm{C}=\mathrm{C}_{\mathrm{o}} \exp \left[\left(\mathrm{H}_{\mathrm{m}}-\mathrm{H}_{\mathrm{n}}\right) / \mathrm{RT}\right]$

$k=k_{0} \exp \left[\left(H_{1}-H_{n}\right) / R T\right]$

where $T$ is the absolute temperature $(K), R$ is the universal gas constant $(\mathrm{J} / \mathrm{molK}), H_{m}$ and $\mathrm{H}_{\mathrm{n}}$ are heat of condensation of mono-and multi-layers of water $(\mathrm{J} / \mathrm{mol})$, respectively, $\mathrm{H}_{\mathrm{l}}$ is the heat of condensation of water vapour $(\mathrm{J} / \mathrm{mol}), \mathrm{C}_{0}$ and $\mathrm{k}_{\mathrm{o}}$ are constants.

$\mathrm{n}_{\mathrm{sm}}, \mathrm{C}$, and $\mathrm{k}$ were obtained by nonlinear regression analysis of experimental data using eq. (1).

The GAB equation was also used by Kiranoudis et al. (1993) to process sorption isotherms of carrots at different temperatures. Eqs. (2) and (3) were applied to calculate the values of $C$ and $k$ at $40^{\circ} \mathrm{C}$, according to the values of $\mathrm{C}_{\mathrm{o}}, \mathrm{k}_{\mathrm{o}}, \mathrm{H}_{\mathrm{I}}, \mathrm{H}_{\mathrm{m}}$ and $\mathrm{H}_{\mathrm{n}}$ reported by Kiranoudis et al. (1993). C, K, and the value of $n_{\mathrm{sm}}$ reported by Kiranoudis et al. (1993) were then processed by eq. (1) and the resulting desorption isotherm was plotted in Figure 1.

The Iglesias and Chirife's equation was used by Iglesias and Chirife (1982) to process sorption isotherms. This equation is expressed as follows: 
$\ln \left[n_{s}+\left(n_{s}^{2}+n_{s 0.5}\right)^{1 / 2}\right]=B_{1} a_{w}+B_{2}$

where $B_{1}$ and $B_{2}$ are parameters to be calculate by nonlinear regression analysis, and $\mathrm{n}_{\mathrm{s} 0.5}$ is the moisture content at $\mathrm{a}_{\mathrm{w}}=0.5$. The values of $\mathrm{n}_{\mathrm{s} 0.5}, \mathrm{~B}_{1}$, and $\mathrm{B}_{2}$ reported by Iglesias and Chirife (1982) were processed by eq. (4) and resulting desorption isotherm was plotted in Figure 1.

Carotenoids. Carrots were blended by a Braun AG 4261 instrument, and 0.125 $\mathrm{g}$ (on dry weight basis) were added to $10 \mathrm{~mL}$ of tetrahydrofuran (THF) stabilized by addition of $0.1 \%$ butylated hydroxytoluene (2,6-di-tert-butyl-p-cresol) (BHT). The mixture was kept refrigerated in an ice bath and mixed by an Ultra-Turrax homogenizer (T25 Janke\&Kunkel IKA Labortechnik) under nitrogen at moderate speed for $2 \mathrm{~min}$. The extract was centrifuged $\left(12,000 \times \mathrm{g}\right.$ at $5^{\circ} \mathrm{C}$ for $\left.10 \mathrm{~min}\right)$, and residual solids were re-extracted with $10 \mathrm{~mL}$ of stabilized THF. The second extract was centrifuged $\left(12,000 \times \mathrm{g}\right.$ at $5^{\circ} \mathrm{C}$ for $\left.10 \mathrm{~min}\right)$. The clarified THF extracts were quantitatively transferred into a volumetric flask, and brought up to $25 \mathrm{~mL}$ with stabilized THF. Extractions were carried out in duplicate. Carotenoid content was analyzed by HPLC as described previously (Lavelli et al., 2000). Briefly, a Vydac 201TP54 C18 column $(250 \mathrm{~mm} \times 4.6 \mathrm{~mm})$, equipped with a C18 precolumn, was used. Chromatographic separation was performed with methanol/stabilized THF (95:5) as an eluent under isocratic conditions, $1.0 \mathrm{~mL} / \mathrm{min}$ flow rate, at room temperature. UV-vis detector was set at $454 \mathrm{~nm}$. $\alpha$ - and $\beta$-carotene were quantified by a calibration curve built with pure $\beta$-carotene, and expressed as $\mathrm{mg} \beta$-carotene equivalents/kg carrots (on dry weight basis).

Statistical analysis of data. Experimental data were processed by one-way ANOVA using the least significant difference (LSD) as a multiple range test, and by regression analysis using Statgraphics 5.1 (STCC Inc.; Rockville, MD).

\section{Results}

\section{Modelling of sorption isotherm}

The experimental data for $a_{w}$ as a function of $n_{s}$ are shown in Figure 1. Several mathematical models have been reported in literature to describe water sorption isotherms of food materials. Among them the GAB model (equation (1) under the Materials and Methods session) was recommended by the European COST 90 project on water activity to standardize sorption isotherm modelling (Spiess and Wolf, 1987). Indeed, the experimental data fitted well the GAB equation $\left(R^{2}=99.65 \%\right)$. The values of $n_{s m}, C$, and $k$, calculated by regression analysis of eq. (1), are shown in Table 2. Estimated value of $n_{\mathrm{sm}}$ was $0.066 \mathrm{Kg} / \mathrm{Kg}$ on dry weight basis, corresponding to the mean $a_{w}$ of 0.33 and the confidence interval of $0.26-0.38$ (on the $95 \%$ probability level).

Carrot sorption isotherms obtained in previous studies under similar temperature conditions are plotted in Figure 1 to allow comparison with our data, and the corresponding parameters of isotherm equations are reported in Table 2. An agreement between our absorption isotherm and that reported by Iglesias and Chirife (1982) to describe both absorption and desorption phenomenon in carrots was found, particularly at the higher $a_{w}$ values. On the contrary, according to Kiranoudis et al. 
(1993) carrots were more hygroscopic, i.e. at each $a_{w}$ more water removal was required with respect to our data.

Table 2 Mathematical Modelling of Carrot Sorption Properties ${ }^{a}$

Product

specifications

$\mathrm{n}_{\mathrm{sm}}$

C

$\mathrm{k}$

source

Freeze dried carrots

at $40^{\circ} \mathrm{C}$

$0.066 \pm 0.043 .6 \pm 0.51 .04 \pm 0.02$ observed

Air-dried carrots

at $37^{\circ} \mathrm{C} \quad 0.051 \quad$ n.d. n.d. Iglesias and Chirife, 1982

Fresh carrots

at $37^{\circ} \mathrm{C} \quad 0.051 \quad$ n.d. n.d. $\quad$ Iglesias and Chirife, 1982

Fresh carrots

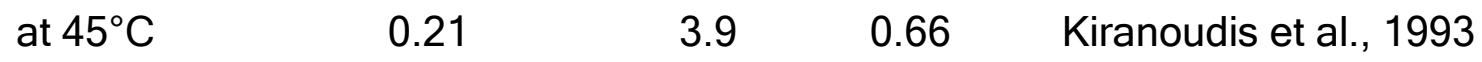

${ }^{\mathrm{a} C}$ Carrots were equilibrated over saturated salt solutions in static desiccator

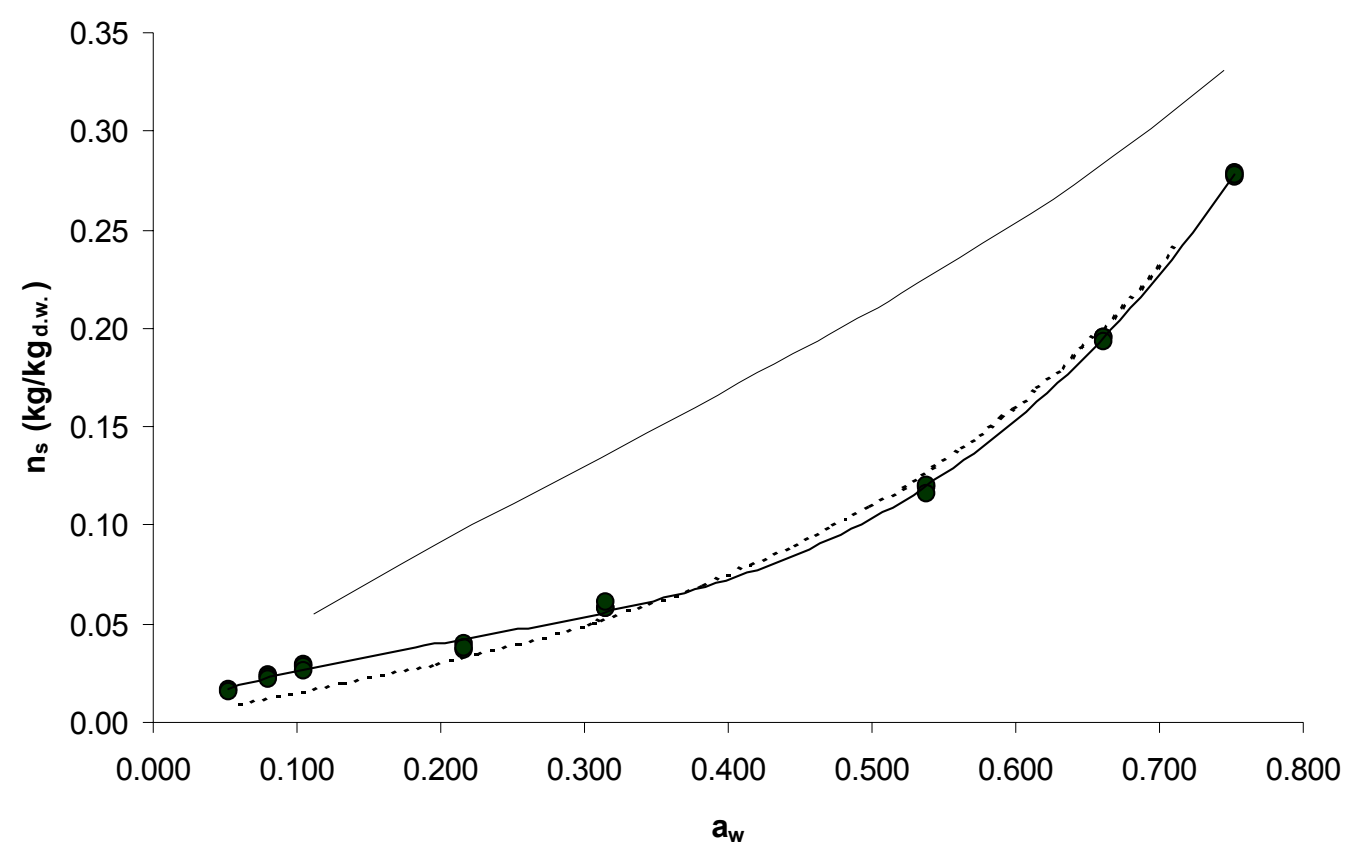

Figure 1. Water sorption properties of carrots: $(\bullet)$, experimental data for freeze dried carrots equilibrated over saturated salt solution in desiccator at $40^{\circ} \mathrm{C}$; (-), adsorption isotherm obtained by fitting experimental data with GAB model; (-) desorption isotherm of carrots at $40^{\circ} \mathrm{C}$ based on data by Kiranoudis et al., 1993; (---) absorption and desorption isotherm of carrots at $37^{\circ} \mathrm{C}$ based on data by Iglesias and Chirife, 1982. 


\section{$A_{w}$ dependence of the rate of carotenoid degradation}

$\alpha$ e $\beta$-carotene contents of freeze-dried carrot lots at the beginning of the storage study are reported in Table 3 . These values were within the concentration range observed in fresh carrots (i.e. $\alpha$-carotene: $259-654 \mathrm{mg} / \mathrm{kg}_{\text {d.w. }} ; \beta$-carotene: 303 - $1005 \mathrm{mg} / \mathrm{kg}_{\text {d.w. }}$ (Sant'Ana et al., 1998).

Table 3. Initial Content of $\alpha$ - and $\beta$-Carotene in Dehydrated Carrots.

\begin{tabular}{lcc}
\hline Carrots $^{\mathrm{a}}$ & $\begin{array}{c}\alpha \text {-carotene } \\
\left(\mathrm{mg} / \mathrm{kg}_{\text {d.w. }}\right)\end{array}$ & $\begin{array}{c}\beta \text {-carotene } \\
\left(\mathrm{mg} / \mathrm{kg}_{\text {d.w. }}\right)\end{array}$ \\
\hline $1 \mathrm{NB}$ & $251 \pm 5$ & $578 \pm 15$ \\
$2 \mathrm{NB}$ & $396 \pm 5$ & $475 \pm 7$ \\
$2 \mathrm{~B}$ & $599 \pm 11$ & $838 \pm 16$ \\
\hline
\end{tabular}

${ }^{\mathrm{a}} 1,2$ are to two different carrot batches; NB, not blanched; B, blanched.
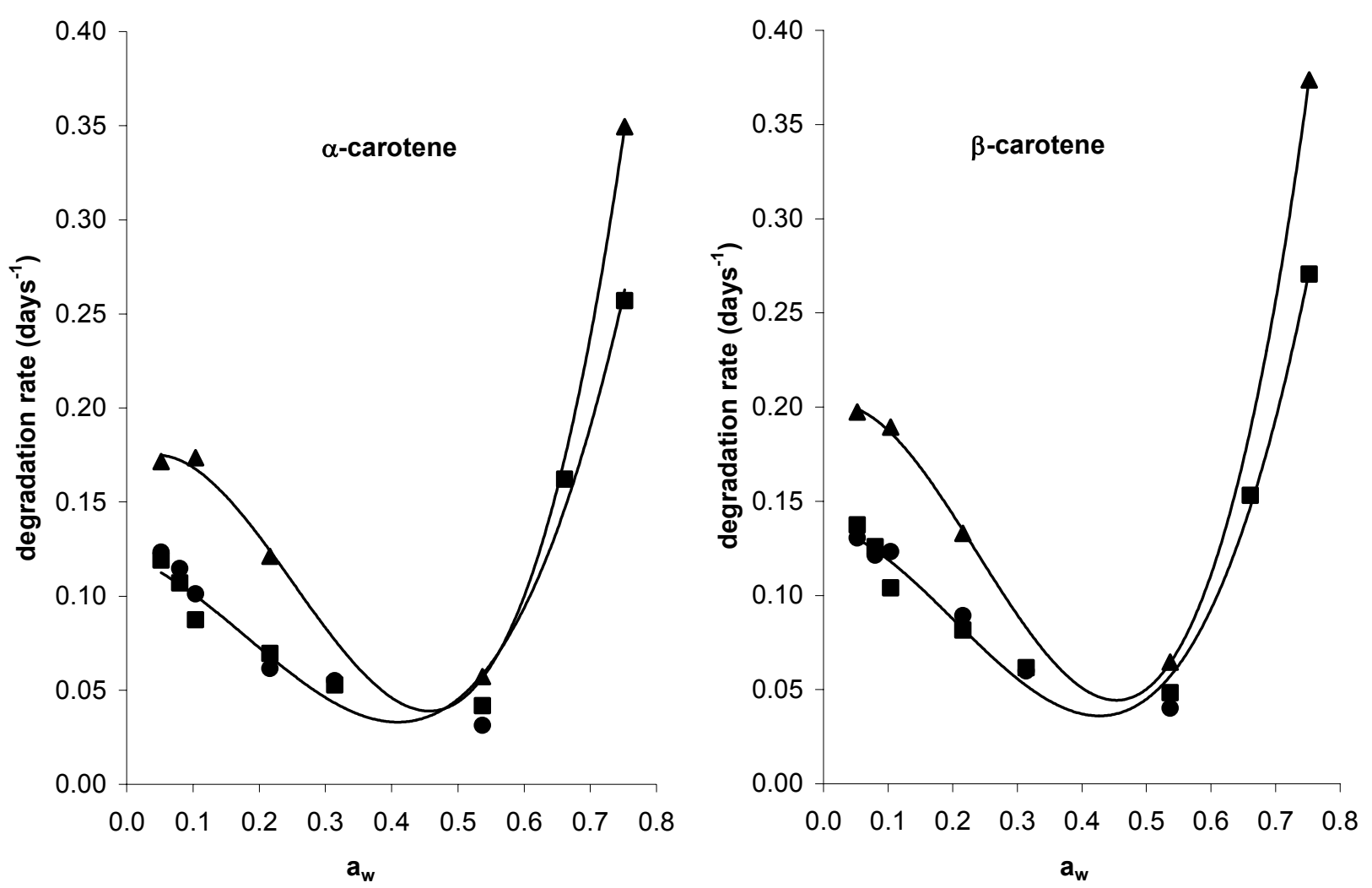

Figure 2. Observed and fitted values of the first-order rate constants for $\alpha$ and $\beta$ carotene degradation in dehydrated carrots at various $a_{w}$, at $40^{\circ} \mathrm{C}$. Symbols represent lots $1 \mathrm{NB}(\bullet), 2 \mathrm{NB}(\boldsymbol{\bullet})$, and $2 \mathrm{~B}(\boldsymbol{\Delta})$.

During storage of dehydrated carrots at $40^{\circ} \mathrm{C}, \alpha$ - and $\beta$-carotene decreased following pseudo-first-order kinetics. Similar behaviour was found between $\alpha$ - and $\beta$ carotene. First-order rate constants for $\alpha$ - and $\beta$-carotene, plotted against $a_{w}$ showed 
an U-shaped curve typical of most oxidative reactions (Labuza, 1971) (Figure 2). In fact a decrease in rate constants was observed with an increase in $a_{w}$ up to about 0.314 . In the $a_{w}$ range of $0.341-0.537$ carotenoids showed the maximum stability. Above these $a_{w}$ values carotenoid stability decreased with a further increase in $a_{w}$ up to 0.754 . The $a_{w}$ range corresponding to maximum carotenoid stability was next to the monolayer $a_{w}$, however it was not symmetrically located with the mean estimated value for monolayer; in fact, it showed a shift towards higher $a_{w}$ values. Accordingly, Arya et al. (1979) found that in dehydrated carrots, stored in the $a_{w}$ range $0.0-0.73$, total carotenoids, as measured spectrophotometrically, were more stable in the $a_{w}$ range of 0.32 - 0.57. The rate constants for carotenoid degradation and the monolayer $a_{w}$ were not reported in this latter study.

\section{Blanching effect on carotenoid content}

As shown in Table 3, the initial carotenoid content of lot 2 NB was lower than that of lot $2 \mathrm{~B}$, due to the stabilizing effect of blanching on carotenoids, which had already been observed (Arya et al., 1979). This effect is generally believed to be due to the inactivation of peroxidase and lipoxidase activity. These enzymes can act during the dehydration process until substrate mobility becomes a limiting factor for catalytic activity. However, the rate of carotenoid degradation was higher in lot $2 \mathrm{~B}$ than in lot 2 NB (Figure 2). This suggests that some substances which stabilize carotenoids are either degraded or leached during blanching (Arya et al., 1979). Alternatively, it may also be argued that blanching causes physical damage to tissues which become more exposed to oxidation (Gomez et al., 2004). Whatever be the mechanism, further investigations are necessary to optimise blanching in order to maximize carotenoid retention in dehydrated carrots.

\section{Rate of carotenoid degradation in carrots as compared to other matrices}

Table 4 presents the results obtained by several authors on the kinetics of $\beta$ carotene degradation in solvents and in some dehydrated systems, in darkness at about $40^{\circ} \mathrm{C}$. Pure $\beta$-carotene is very unstable; the pseudo-zero-order rate constants in cyclohexane and ethanol and the pseudo-first-order rate constant in water, at $35^{\circ} \mathrm{C}$ are $19.1,22.1$, and 0.12 days $^{-1}$, respectively (Minguez-Mosquera and Jaren-Galan, 1995).

In microcrystalline cellulose powder, $\beta$-carotene stability is enhanced (Baloch et al., 1977). In fact, at $\mathrm{a}_{\mathrm{w}}$ of 0.31 , under $75 \% \mathrm{~N}_{2}$ and $25 \% \mathrm{O}_{2}$ as a storage atmosphere, the first-order rate constant for $\beta$-carotene degradation is 0.070 days $\mathrm{s}^{-1}$ at $37^{\circ} \mathrm{C}$. The stability of $\beta$-carotene is considerably enhanced by $\mathrm{SO}_{2}$ addition ( $\mathrm{k}$ at $37^{\circ} \mathrm{C}=0.0036$ days $^{-1}$ ) or by $\mathrm{O}_{2}$ exclusion in the atmosphere $\left(\mathrm{k}\right.$ at $37^{\circ} \mathrm{C}=0.022$ days $\left.^{-1}\right)$.

Encapsulation of $\beta$-carotene with maltodextrin is another means to protect carotenoids from oxidation (Wagner and Warthesen, 1995; Desobry et al., 1997). Studies indicated that the higher dextrose equivalent (DE) starch forms a tighter and more gas impermeable matrix and provides a greater carotenoid stability. In fact, the first-order rate constants for encapsulated $\beta$-carotene in the $a_{w}$ range $0.154-0.178$, under air, at $40^{\circ} \mathrm{C}$, are 0.031 and 0.014 days $^{-1}$ in $4 \mathrm{DE}$ and $36.5 \mathrm{DE}$ powders, respectively (Wagner and Warthesen, 1995). On the other hand, hygroscopicity is also dependent on the $\mathrm{DE}$. In general, the higher the $\mathrm{DE}$, the higher the hygroscopicity, which can lead to moisture uptake during storage. Therefore, it was decided to use a 25 DE maltodextrin as an encapsulating agent (Desobry et al., 1998). The first-order rate constants of $\beta$-carotene in this latter system range from 0.027 to 0.044 days $^{-1}$, depending on the drying technology (Desobry et al., 1997). 
Our data showed that carrots naturally provide protection for carotenoids. In fact, in the maximum stability $a_{w}$ range $(0.341-0.537)$ the first-order rate constants for carotenoid degradation were comparable with those observed by the other authors with maltodextrin or microcrystalline cellulose as matrices.

Table 4. Rate Constants for $\beta$-Carotene Degradation in Solvents and Dehydrated Systems in Darkness

Model systems

\begin{tabular}{ccc}
\hline \multicolumn{3}{l}{$\beta$-carotene in solvents (Minguez-Mosquera and Jaren-Galan, 1995) } \\
\hline & Storage conditions & $\mathrm{k}\left(\right.$ days $\left.^{-1}\right)$ \\
\cline { 2 - 3 } cyclohexane & $35^{\circ} \mathrm{C}$ & $19.1^{\mathrm{a}}$ \\
ethanol & $35^{\circ} \mathrm{C}$ & $22.6^{\mathrm{a}}$ \\
water & $35^{\circ} \mathrm{C}$ & $0.12^{\mathrm{b}}$
\end{tabular}

$\beta$-carotene in microcrystalline cellulose (Baloch et al., 1977)

\begin{tabular}{lll} 
& \multicolumn{1}{l}{ Storage conditions } & (days $^{-1}$ ) \\
\cline { 2 - 3 } non sulphited & $\mathrm{a}_{\mathrm{w}} 0.31,75 \% \mathrm{~N}_{2} 25 \% \mathrm{O}_{2}, 37^{\circ} \mathrm{C}$ & $0.070^{\mathrm{b}}$ \\
non sulphited & $\mathrm{a}_{\mathrm{w}} 0.31,100 \% \mathrm{~N}_{2}, 37^{\circ} \mathrm{C}$ & $0.022^{\mathrm{b}}$ \\
sulphited & $\mathrm{a}_{\mathrm{w}} 0.31,75 \% \mathrm{~N}_{2} 25 \% \mathrm{O}_{2}, 37^{\circ} \mathrm{C}$ & $0.0036^{\mathrm{b}}$ \\
$(2050 \mathrm{ppm})$ & &
\end{tabular}

Spray-dried carrot juice $+20 \%$ hydrolyzed starch (Wagner and Warthesen, 1995)

\begin{tabular}{lll}
$4 \mathrm{DE}$ & Storage conditions & $\mathrm{k}\left(\right.$ days $\left.^{-1}\right)$ \\
\cline { 2 - 3 } $25 \mathrm{DE}$ & $\mathrm{a}_{\mathrm{w}} 0.154-0.178$, air, $40^{\circ} \mathrm{C}$ & $0.031^{\mathrm{b}}$ \\
$36.5 \mathrm{DE}$ & $\mathrm{a}_{\mathrm{w}} 0.154-0.178$, air, $40^{\circ} \mathrm{C}$ & $0.025^{\mathrm{b}}$ \\
& $\mathrm{a}_{\mathrm{w}} 0.154-0.178$, air, $40^{\circ} \mathrm{C}$ & $0.014^{\mathrm{b}}$
\end{tabular}

$\beta$-carotene in 25 DE maltodextrin (Desobry et al., 1997)

\begin{tabular}{lll} 
& Storage conditions & $\mathrm{k}\left(\right.$ days $\left.^{-1}\right)$ \\
\cline { 2 - 3 } spray-dried & $\mathrm{a}_{\mathrm{w}} 0.32$, air, $40^{\circ} \mathrm{C}$ & $0.044^{\mathrm{b}}$ \\
drum-dried & $\mathrm{a}_{\mathrm{w}} 0.32$, air, $40^{\circ} \mathrm{C}$ & $0.027^{\mathrm{b}}$ \\
freeze-dried & $\mathrm{a}_{\mathrm{w}} 0.32$, air, $40^{\circ} \mathrm{C}$ & $0.044^{\mathrm{b}}$
\end{tabular}

Freeze-dried carrots (observed)

Storage conditions $\mathrm{k}\left(\right.$ days $\left.^{-1}\right)$

$\begin{array}{lll}\text { not blanched } & \mathrm{a}_{\mathrm{w}} 0.537, \text { air, } 40^{\circ} \mathrm{C} & 0.044^{\mathrm{b}} \\ \text { not blanched } & \mathrm{a}_{\mathrm{w}} 0.314, \text { air, } 40^{\circ} \mathrm{C} & 0.061^{\mathrm{b}} \\ \text { blanched } & \mathrm{a}_{\mathrm{w}} 0.537, \text { air, } 40^{\circ} \mathrm{C} & 0.065^{\mathrm{b}}\end{array}$

a pseudo zero-order kinetics: $\mathrm{C} / \mathrm{C}_{0}=1-\mathrm{kt}$

${ }^{\mathrm{b}}$ pseudo first-order kinetics: $\ln \left(\mathrm{C} / \mathrm{C}_{0}\right)=-\mathrm{kt}$

Conclusions

The results of this study lead to some practical points about processing and storage conditions required to maintain high carotenoid contents in dehydrated 
carrots. Partial dehydration of carrots to intermediate moisture levels could be proposed instead of removing water completely, according to the following rules:

a) reducing $a_{w}$ values to $0.31-0.54$, corresponding to $6-11 \%$ of moisture (on wet weight basis). In this $a_{w}$ range microbial growth is arrested, enzymatic activity and non-enzymatic browning are at minimum (Labuza, 1971), and our data indicate maximum carotenoid stability;

b) alternatively, reducing $a_{w}$ values to $0.54-0.75$, corresponding to $11-22 \%$ of moisture (on wet weight basis). In this $a_{w}$ range the microbial growth rate and the enzymatic activity are still at minimum; however, the most effective factors which account for carotenoid stability are still to be investigated. Furthermore, the occurrence of non-enzymatic browning can not be ruled out (Labuza, 1971).

Both criteria should be combined with optimised packaging conditions, which reduce exposure of product to air and light during storage.

\section{Acknowledgment}

We would like to thank MURST (Ministry for University and Scientific and Technological Research) for supporting the strategic project: Methodologies and Integrated Systems for qualification of Horticultural Productions from Fucino (law 449/97), M.D. May 10, 2000.

\section{Literature cited}

AOAC, 1980, Official Methods of Analysis. $13^{\text {th }}$ edn, Association of Official Analytical Chemists, Washington.

Arya, S.S.; Natesan, V.; Parihar, D.B.; Vijayaraghavan, P.K. 1979 J. Food Technol., 14, 579.

Baloch, A.K.; Buckle, K.A.; Edwards, R.A. 1977 J. Food Technol., 12, 309.

Brennan, J.G. 1994. Food dehydration. A dictionary and guide. Campbell-Platt, G. Ed. Butterworth-Heinemann Ltd, Oxford.

Desobry, S.A.; Netto, F.M.; Labuza, T.P. 1997 J. Food Sci., 62, 1158.

Desobry, S.A.; Netto, F. M.; Labuza T.P. 1998 Crit. Rev. Food Sci. Nutr., 38, 381.

El-Arab, A.E.; Khalil, F.; Hussein, L. 2002 Int. J. Food Sci. Nutr., 53, 465.

Goldman, M.; Horev, B.; Saguy, I. 1983 J. Food Sci., 48, 751.

Gomez, F.; Toledo, R. T.; Wadso, L.; Gekas, V.; Sjoholm, I. 2004 J. Food Eng., 65, 173.

Greenspan, L. 1977 J. Res. Nat. Bur. Stand. A (Phys. and Chem.), 81, 89.

Iglesias, H.A.; Chirife, J. 1982. Handbook of food isotherms: water sorption parameters for food and food components. Food science and technology - A series of monographs. Academic Press, New York.

Kiranoudis, C.T.; Maroulis, Z.B.; Tsami, E.; Marinos-Kouris, D. 1993 J. Food Eng., $20,55$.

Labuza, T.P. 1971 Crit. Rev. Food Technol., 2, 355.

Lavelli, V.; Peri, C.; Rizzolo, A. 2000 J. Agric. Food Chem., 48, 1442.

Lavelli, V.; Pagliarini, E.; Ambrosoli, R.; Minati, J.L.; Zanoni, B. 2006 Postharvest Biol. Technol. 40, 34.

Minguez-Mosquera, M.I.; Jaren-Galan M. 1995 J. Sci. Food Agric, 67, 153. 
Sant'Ana, H.; Stringheta, P.C.; Brandao, S.; Cordeiro de Azeredo R. 1998 Food Chem., 61, 145.

Spiess, W. E. L.; Wolf, W. 1987. Critical evaluation of methods to determine moisture sorption isotherms. In: Water activity: theory and applications to food, pp. 215233. L. B. Rockland \& L. R. Beuchat, Eds., Marcel Dekker, New York.

Wagner, L. A.; Warthesen, J. J. 1995 J. Food Sci., 60, 1048.

Yeum, K.J.; Russell, R.M. 2002 Ann. Rev. Nutr. 22, 483.

Zanoni, B; Lavelli, V.; Ambrosoli, R.; Garavaglia, L.; Minati, J.L.; Pagliarini, E. 2006 J. Food Eng, in press 